\title{
Association between ultrasound images and patient-reported outcomes in the treatment of rheumatoid arthritis: a retrospective study
}

\author{
Masao Nawata 1,2, Kazuki Someya ${ }^{1,2}$, Masashi Funada², Yuya Fujita², Atsushi Nagayasu², Kazuyoshi Saito ${ }^{1,2}$ and \\ Yoshiya Tanaka ${ }^{2 *}$
}

\begin{abstract}
Background: Improvements in the treatment of rheumatoid arthritis (RA) have made it possible to achieve treatment goals. It has been reported that both residual synovitis caused by RA and the patients' subjective symptoms remain even after achieving the treatment goals; however, there are limited reports showing a relationship between them. Furthermore, no studies have evaluated the relationship between patient-reported outcomes (PROs) and subclinical synovitis measured by musculoskeletal ultrasonography (MSUS) in the treatment of RA. This study aimed to investigate residual symptoms and residual synovitis due to remission (REM) or low disease activity (LDA).
\end{abstract}

Methods: We performed MSUS on 300 patients with RA who attended our hospital for routine care, and we analysed them cross-sectionally by disease activity. Grayscale (GS) and power Doppler (PD) synovitis was evaluated in 22 bilateral hand joints using MSUS. We first performed univariate and multivariate analysis by dividing the data by disease activity. Next, we analysed each PRO in the obtained MSUS results.

Results: A multivariate analysis of high disease activity (HDA)/moderate disease activity (MDA) vs. LDA/ REM group identified tender joint count (TJC), pain visual analog scale (VAS) score, and presence or absence of GS score $\geq 2$. The one-way analysis of the relationship between the presence or absence of GS score $\geq 2$ and each PRO showed a significant difference. In contrast, a multivariate analysis of LDA vs. REM group identified TJC and fatigue VAS score. In REM, PROs alone were relevant, and there was no correlation with MSUS.

Conclusion: We found that the residual inflammation in the ultrasound images was associated with PROs in the LDA group, but not in the REM group.

Trial registration Retrospectively registered.

Keywords: Grayscale, Musculoskeletal ultrasonography, Patient-reported outcomes, Residual symptoms, Rheumatoid arthritis

*Correspondence: tanaka@med.uoeh-u.ac.jp

${ }^{2}$ The First Department of Internal Medicine, School of Medicine, University of Occupational and Environmental Health, 1-1 Iseigaoka, Yahata-nishi-ku, Kitakyushu, Fukuoka 807-8555, Japan

Full list of author information is available at the end of the article

\section{Background}

Rheumatoid arthritis (RA) is a chronic inflammatory disorder of unknown cause with various clinical symptoms [1]. In 2010, a treatment strategy known as treat-to-target (T2T) was proposed; with T2T, the treatment goal is clarified, and strict control is attained to achieve that 
goal. This is a crucial process in RA treatment to prevent future joint destruction. The therapeutic goal in the treatment process is clinical remission (REM) or low disease activity (LDA) [2]. Additionally, the 2019 update of the European League Against Rheumatism (EULAR) recommendations stated that the treatment for all patients with RA should aim at achieving persistent REM or LDA [3].

In recent years, with improvements in the treatment of RA making it possible to achieve treatment goals, the management of patients' subjective symptoms has received more attention in the context of patient-centred care [4]. As a result, subjective patient evaluations, known as patient-reported outcomes (PROs), have been considered. PROs refer to any health measures obtained directly from the patient (i.e., patient response is not interpreted by a physician or other members of the care team); they include simple symptoms (e.g., pain), and more complex concepts, such as daily life activities, and physical, psychological, and social aspects, comprising more than one inflammation score [5].

In contrast, the ultrasound (US) image of RA has changed significantly with recent advances. Musculoskeletal ultrasonography (MSUS) is used by rheumatologists in clinical practice and has been reported to exhibit high detectability of synovitis and sensitivity comparable to magnetic resonance imaging (MRI) [6, 7]. The residual synovitis caused by RA and the patients' subjective symptoms remain even after achieving the treatment goals. Therefore, we hypothesized that residual synovitis would be associated with subjective symptoms.

This study aimed to investigate residual symptoms and residual synovitis due to remission or low disease activity.

\section{Methods}

\section{Patients and study design}

Altogether, 300 patients with RA who underwent MSUS and attended our hospital for routine care were enrolled in the study; cross-sectional analysis by disease activity was performed for the patients. Patients with RA $>20$ years of age who received at least one diseasemodifying antirheumatic drug (DMARD) continuously for at least 24 weeks were included. All patients underwent US scanning for arthritis evaluation and were diagnosed with RA according to the 1987 American Rheumatism Association revised criteria or the 2010 American College of Rheumatology/EULAR classification criteria [8-10].

Demographic and clinical characteristics were obtained from medical records, including age, sex, disease duration, oral steroid use, methotrexate (MTX) use, biological (targeted synthetic) (b[ts]) DMARD use, tender joint count (TJC), swollen joint count (SJC), erythrocyte sedimentation rate (ESR), C-reactive protein (CRP) level, matrix metalloproteinase-3 (MMP-3) level, rheumatoid factor, anti-cyclic citrullinated peptide antibody level, and PROs (morning stiffness, pain visual analog scale [VAS] score, and fatigue VAS score).

The objective of this study was to investigate the residual symptoms and residual synovitis due to remission (REM) or (LDA). The study and its retrospective observation design was approved by the Ethics Committee of the Japan Physicians Association, and informed consent was obtained from all patients. The research was conducted in accordance with the Ethical Guidelines for Medical and Health Research Involving Human Subjects.

\section{Treatment}

Treatment involved the use of conventional synthetic DMARDs, including MTX. b(ts)DMARDs were prescribed to patients with RA who did not respond adequately to conventional synthetic DMARD therapy according to the guidelines of the Japan College of Rheumatology.

\section{Ultrasonography}

Clinical assessment by US scanning was performed bilaterally at identical time points for the wrist (intracarpal, radiocarpal, and ulnocarpal recesses), first to fifth metacarpophalangeal joints, first interphalangeal joints, and second to fifth proximal interphalangeal joints (dorsal recess) by a single-trained sonographer (S.K.) with 10 years of experience, using MSUS.

The MSUS examinations were performed with TOSHIBA Aplio 300 ultrasound machines (Toshiba Medical Systems Corp., Otawara, Japan) using a linear transducer $(12 \mathrm{MHz})$. No changes in the US settings were made during the study, and no software was upgraded.

Systematic multiplanar grayscale (GS) US and power Doppler (PD) US examinations were performed on 22 joints in a standardized manner based on the EULAR guidelines [11]. Each joint was scored using a semiquantitative scale of $0-3$ for GS, defined as follows: grade 0, absence of synovial hypertrophy on GS, no synovial thickening; grade 1, mild or minimal synovial thickening filling the angle between the periarticular bones without bulging over the line linking the tops of the bones; grade 2, moderate synovial thickening bulging over the line linking the tops of the periarticular bones, but without extension to at least one bone diaphysis; and grade 3, marked synovial thickening bulging over the line linking the tops of the periarticular bones and with extension to at least one of the bone diaphysis. The semiquantitative scale of $0-3$ for PD [12] was as follows: grade 0 , no PD signal and no synovial flow; grade 1, mild, single-vessel signal; grade 2, moderate, confluent signal in less than half of the synovial area; and grade 3 , marked PD signal 
in more than half of the synovial area. The US score was calculated as the GS score and PD score (range, 0-66), respectively.

\section{Clinical assessment}

Disease activity was assessed using the Simplified Disease Activity Index (SDAI) [13, 14]. Functional impairment was assessed using the Health Assessment Questionnaire Disability Index (HAQ-DI) [15]. Quality of life (QoL) was assessed using the European Quality of Life-5 Dimensions (EQ-5D-5L) questionnaire [16]. Responses to the EQ-5D-5L were converted to a QoL score using Japanese value sets [17].

\section{Statistical analyses}

We assessed the correlations between clinical and US variables. We performed multivariate analysis by dividing the data by disease activity. We first divided the analysis into two groups: those who achieved LDA and those who did not. Next, we divided the analysis into REM and LDA. Finally, we analysed each PRO in the obtained US results. A univariate analysis was performed using the Wilcoxon signed-rank test and likelihood ratio test. $P<0.05$ was considered statistically significant. To identify independent variables, a multivariate logistic regression analysis of variables that were significant in the univariate analysis was performed using the stepwise method.

To perform stratified analyses of GS scores (focused on the presence or absence of GS score $\geq 2$ identified by multivariate analysis), the Wilcoxon signed-rank test was used to evaluate the relationship between the presence or absence of GS findings and each PRO. All analyses were conducted using JMP version 11.0 (SAS Institute Inc, Cary, NC, USA).

\section{Results}

\section{Patient characteristics}

The mean age of the 300 patients with RA was 65.4 years; the percentage of females was 80.7; and the mean disease duration was 103.6 months. Other patient characteristics were as follows: MTX use, $63.7 \%$; mean MTX dose, $8.7 \mathrm{mg} /$ week; steroid use, $12.7 \%$; mean steroid dose, $4.7 \mathrm{mg} /$ day (in prednisolone); $\mathrm{b}(\mathrm{ts})$ DMARD usage rate, 37.7\%; and overall mean SDAI, 10.6. The mean values for the PROs were as follows: morning stiffness, $145.0 \mathrm{~min}$; pain VAS score, $31.2 \mathrm{~mm}$; and fatigue VAS score, $32.4 \mathrm{~mm}$. The mean MSUS score was 3.1 for the total GS score and 1.3 for the total PD score. The rates of GS and PD findings were as follows: GS score $\geq 1,65.7 \%$; GS score $\geq 2$, 36.0\%; GS score $\geq 3,14.3 \%$; PD score $\geq 1$, 34.0\%; PD score $\geq 2,22.7 \%$; and PD score $\geq 3,2.7 \%$ (Table 1).
Table 1 Patient background

\begin{tabular}{|c|c|}
\hline Characteristics & $\begin{array}{l}\text { All patients } \\
(\mathrm{N}=300)\end{array}$ \\
\hline Age, years & $65.4 \pm 14.4$ \\
\hline Female, \% & 80.7 \\
\hline Disease duration, months & $103.6 \pm 119.6$ \\
\hline Stage $(I / I / I I I / I V), \%$ & $44.7 / 26.7 / 14.7 / 13.9$ \\
\hline TJC, $0-28$ & $2.9 \pm 4.2$ \\
\hline SJC, 0-28 & $1.7 \pm 3.2$ \\
\hline $\mathrm{CRP}, \mathrm{mg} / \mathrm{dL}$ & $0.8 \pm 1.8$ \\
\hline $\mathrm{ESR}, \mathrm{mm} / \mathrm{h}$ & $24.4 \pm 24.7$ \\
\hline $\mathrm{RF}, \mathrm{IU} / \mathrm{mL}$ & $121.8 \pm 216.8$ \\
\hline RF positive, $\%$ & 61.2 \\
\hline $\mathrm{CCP}, \mathrm{U} / \mathrm{mL}$ & $250.9 \pm 405.3$ \\
\hline CCP positive, $\%$ & 66.5 \\
\hline $\mathrm{MMP}-3, \mathrm{ng} / \mathrm{mL}$ & $131.6 \pm 229.6$ \\
\hline SDAl & $10.6 \pm 11.7$ \\
\hline MTX use, $\%$ & 63.7 \\
\hline MTX, mg/w & $8.7 \pm 3.4$ \\
\hline PSL use, \% & 12.7 \\
\hline $\mathrm{PSL}, \mathrm{mg} / \mathrm{d}$ & $4.7 \pm 3.4$ \\
\hline b(ts)DMARD use, $\%$ & 37.7 \\
\hline HAQ-DI & $0.8 \pm 0.9$ \\
\hline EQ-5D-5L & $0.7 \pm 0.2$ \\
\hline $\mathrm{MS}, \min$ & $145.0 \pm 398.6$ \\
\hline Pain VAS score, $0-100, \mathrm{~mm}$ & $31.2 \pm 29.1$ \\
\hline Fatigue VAS score, 0-100, mm & $32.4 \pm 29.8$ \\
\hline $\mathrm{EGA}, 0-100, \mathrm{~mm}$ & $16.4 \pm 19.1$ \\
\hline GS sum & $3.1 \pm 5.1$ \\
\hline GS score $\geq 1, \%$ & 65.7 \\
\hline GS score $\geq 2, \%$ & 36.0 \\
\hline GS score $\geq 3, \%$ & 14.3 \\
\hline PD sum & $1.3 \pm 3.0$ \\
\hline PD score $\geq 1, \%$ & 34.0 \\
\hline PD score $\geq 2, \%$ & 22.7 \\
\hline PD score $\geq 3, \%$ & 2.7 \\
\hline
\end{tabular}

Results are shown as means $\pm \mathrm{SDs}$; TJC, tender joint count; SJC, swollen joint count; CRP, C-reactive protein; ESR, erythrocyte sedimentation rate; $\mathrm{RF}$, rheumatoid factor; CCP, cyclic citrullinated peptide; MMP-3, matrix metalloproteinase-3; SDAI, Simplified Disease Activity Index; MTX, methotrexate; PSL, prednisolone; $b(t s) D M A R D$, biological (targeted synthetic) diseasemodifying antirheumatic drug; HAQ-DI, Health Assessment Questionnaire Disability Index; EQ-5D-5L, European Quality of Life-5 Dimensions; MS, morning stiffness; VAS, visual analog scale; EGA, evaluator global assessment of disease activity; GS, grayscale; PD, power Doppler

\section{Correlations between clinical and US variables}

We examined the correlation between SDAI and the sum of the GS score or sum of the PD score. The correlation coefficient between SDAI and the sum of GS was $0.4808(P<0.0001)$, and that between SDAI and the sum of PD was $0.5007(P<0.0001)$. Therefore, a positive correlation existed between the SDAI and the sum of the GS and PD scores. 


\section{Comparison of PROs, clinical characteristics, and US} characteristics of the HDA/MDA and LDA/REM groups

Patient data were analysed after they were classified into the HDA/MDA $(\mathrm{N}=106)$ and LDA/REM $(\mathrm{N}=194)$ groups. The univariate analysis identified many significant factors, including TJC, SJC, CRP, ESR, MMP-3 value, MTX usage rate, MTX dose, $b(t)$ DMARD usage rate, HAQ, EQ-5D-5L, morning stiffness, pain VAS score, fatigue VAS score, EGA, total GS score, GS score $\geq 1$, GS score $\geq 2$, GS score $\geq 3$, total PD score, PD score $\geq 1$, and PD score $\geq 2$ (Table 2). The subsequent multivariate analysis identified the following independently significant factors: TJC, CRP, pain VAS score, MTX dose, and the presence or absence of GS score $\geq 2$ (Table 3). Although low TJC scores, low levels of CRP, low pain VAS score, and the use of sufficient MTX are already known to maintain REM or LDA, we focused on GS score $\geq 2$.

\section{GS score $\geq 2$ and GS score $<2$ and the relevance to each PRO}

The one-way analysis of the relationship between the presence or absence of GS score $\geq 2$ and each PRO showed a significantly longer duration of morning

Table 2 Patient background of the HDA/MDA and LDA/REM groups

\begin{tabular}{|c|c|c|c|}
\hline Characteristics & $\begin{array}{l}\text { HDA/MDA } \\
(\mathrm{N}=105)\end{array}$ & $\begin{array}{l}\text { LDA/REM } \\
(\mathrm{N}=195)\end{array}$ & $P$ \\
\hline Age, years & $65.3 \pm 14.2$ & $65.5 \pm 14.6$ & 0.7303 \\
\hline Female, \% & 78.1 & 81.5 & 0.4742 \\
\hline Disease duration, months & $108.5 \pm 145.7$ & $101.0 \pm 103.0$ & 0.1375 \\
\hline Stage (I/II/III/IV), \% & 42.7/19.1/19.1/19.1 & $45.7 / 30.8 / 12.3 / 11.2$ & 0.0337 \\
\hline TJC, 0-28 & $6.7 \pm 5.1$ & $0.9 \pm 0.1$ & $<0.0001$ \\
\hline SJC, $0-28$ & $4.4 \pm 4.3$ & $0.3 \pm 0.6$ & $<0.0001$ \\
\hline $\mathrm{CRP}, \mathrm{mg} / \mathrm{dL}$ & $1.7 \pm 2.7$ & $0.3 \pm 0.6$ & $<0.0001$ \\
\hline $\mathrm{ESR}, \mathrm{mm} / \mathrm{h}$ & $35.5 \pm 31.9$ & $18.5 \pm 17.4$ & $<0.0001$ \\
\hline $\mathrm{RF}, \mathrm{IU} / \mathrm{mL}$ & $176.6 \pm 276.5$ & $92.5 \pm 170.7$ & 0.1713 \\
\hline RF positive, $\%$ & 63.5 & 60.0 & 0.5585 \\
\hline $\mathrm{CCP}, \mathrm{U} / \mathrm{mL}$ & $322.1 \pm 533.7$ & $212.8 \pm 310.9$ & 0.6343 \\
\hline CCP positive, $\%$ & 66.7 & 66.5 & 0.9751 \\
\hline MMP-3, ng/mL & $225.7 \pm 348.9$ & $78.5 \pm 80.4$ & $<0.0001$ \\
\hline SDAI & $22.9 \pm 11.8$ & $4.0 \pm 3.2$ & $<0.0001$ \\
\hline MTX use, \% & 53.3 & 69.2 & 0.0063 \\
\hline MTX, mg/w & $8.9 \pm 3.2$ & $8.6 \pm 3.5$ & 0.0389 \\
\hline PSL use, \% & 13.3 & 12.3 & 0.7989 \\
\hline $\mathrm{PSL}, \mathrm{mg} / \mathrm{d}$ & $5.8 \pm 4.4$ & $4.0 \pm 2.6$ & 0.7517 \\
\hline b(ts)DMARD use, $\%$ & 29.5 & 42.1 & 0.0327 \\
\hline HAQ-DI & $1.5 \pm 0.8$ & $0.5 \pm 0.7$ & $<0.0001$ \\
\hline EQ-5D-5L & $0.6 \pm 0.2$ & $0.8 \pm 0.1$ & $<0.0001$ \\
\hline$M S$, min & $332.5 \pm 568.2$ & $46.2 \pm 210.9$ & $<0.0001$ \\
\hline Pain VAS score, $0-100, \mathrm{~mm}$ & $59.6 \pm 24.0$ & $16.0 \pm 18.2$ & $<0.0001$ \\
\hline Fatigue VAS score, 0-100, mm & $58.1 \pm 25.3$ & $18.7 \pm 22.1$ & $<0.0001$ \\
\hline $\mathrm{EGA}, 0-100, \mathrm{~mm}$ & $35.2 \pm 20.2$ & $6.4 \pm 7.2$ & $<0.0001$ \\
\hline GS sum & $5.5 \pm 7.1$ & $1.8 \pm 2.9$ & $<0.0001$ \\
\hline GS score $\geq 1, \%$ & 82.9 & 56.4 & $<0.0001$ \\
\hline GS score $\geq 2, \%$ & 59.0 & 23.6 & $<0.0001$ \\
\hline GS score $\geq 3, \%$ & 25.7 & 8.2 & $<0.0001$ \\
\hline PD sum & $2.6 \pm 4.3$ & $0.6 \pm 1.7$ & $<0.0001$ \\
\hline PD score $\geq 1, \%$ & 55.2 & 22.6 & $<0.0001$ \\
\hline PD score $\geq 2, \%$ & 40.0 & 13.3 & $<0.0001$ \\
\hline PD score $\geq 3, \%$ & 2.9 & 2.6 & 0.8806 \\
\hline
\end{tabular}

Results are shown as means \pm SDs; TJC, tender joint count; SJC, swollen joint count; CRP, C-reactive protein; ESR, erythrocyte sedimentation rate; RF, rheumatoid factor; CCP, cyclic citrullinated peptide; MMP-3, matrix metalloproteinase-3; SDAI, Simplified Disease Activity Index; MTX, methotrexate; PSL, prednisolone; b(ts)DMARD, biological (targeted synthetic) disease-modifying antirheumatic drug; HAQ-DI, Health Assessment Questionnaire Disability Index; EQ-5D-5L, European Quality of Life-5 Dimensions; MS, morning stiffness; VAS, visual analog scale; EGA, evaluator global assessment of disease activity; GS, grayscale; PD, power Doppler; LDA, low disease activity; HDA: high disease activity; MDA: moderate disease activity; REM: remission 
Table 3 Multivariate logistic analysis of the HDA/MDA and LDA/REM groups

\begin{tabular}{|c|c|c|c|c|c|}
\hline & Estimated value & Standard error & Chi-square & Confidence interval & $P$ \\
\hline Intercept & 3.5585 & 0.5112 & 48.46 & 2.6319 to -4.6485 & $<0.0001$ \\
\hline TJC & -0.2616 & 0.0756 & 12.50 & -0.4286 to -0.1337 & 0.0004 \\
\hline CRP & -0.4987 & 0.2370 & 4.52 & -0.9701 to -0.0598 & 0.0336 \\
\hline Pain VAS score & -0.0645 & 0.0099 & 42.35 & -0.0854 to -0.0463 & $<0.0001$ \\
\hline MTX, mg/w & 0.1002 & 0.0472 & 4.51 & $0.0099-0.1963$ & 0.0338 \\
\hline b(ts)DMARD: yes, $1 ;$ no, 0 & -0.2943 & 0.2284 & 1.66 & -0.7553 to 0.1466 & 0.1976 \\
\hline GS score $\geq 2$ : yes, 1 ; no, 0 & 0.5359 & 0.2284 & 5.45 & $0.0896-0.9970$ & 0.0153 \\
\hline
\end{tabular}

TJC, tender joint count; CRP, C-reactive protein; VAS, visual analog scale; MTX, methotrexate; b(ts)DMARD, biological (targeted synthetic) disease-modifying antirheumatic drug; GS, grayscale; LDA, low disease activity; HDA: high disease activity; MDA: moderate disease activity; REM: remission

stiffness (Fig. 1A), higher pain VAS score (Fig. 1B), higher fatigue VAS score (Fig. 1C), higher HAQ-DI (Fig. 1D), and lower EQ-5D-5L (Fig. 1E) for patients with GS score $\geq 2$ (Fig. 1). Therefore, it was suggested that morning stiffness, fatigue, and joint pain due to RA may persist as residual symptoms in patients with GS score $\geq 2$.

\section{Comparison of PROs, clinical characteristics, and US characteristics of the LDA and REM groups}

Patient data were analysed once they were classified into LDA $(\mathrm{N}=96)$ and REM $(\mathrm{N}=99)$ groups. The univariate analysis identified several significant factors, including TJC, SJC, MTX usage rate, MTX dose, HAQ, EQ-5D-5L, morning stiffness, pain VAS score, fatigue VAS score, EGA, total GS score, GS score $\geq 1$, GS score $\geq 2$, total PD score, and PD score $\geq 1$ (Table 4). The subsequent multivariate analysis identified the independent significant factors (TJC and fatigue VAS score) (Table 5). For patients with LDA not achieving REM, it was suggested that fatigue VAS score and TJC may remain. In patients who achieved REM, little residual inflammation was observed on MSUS.
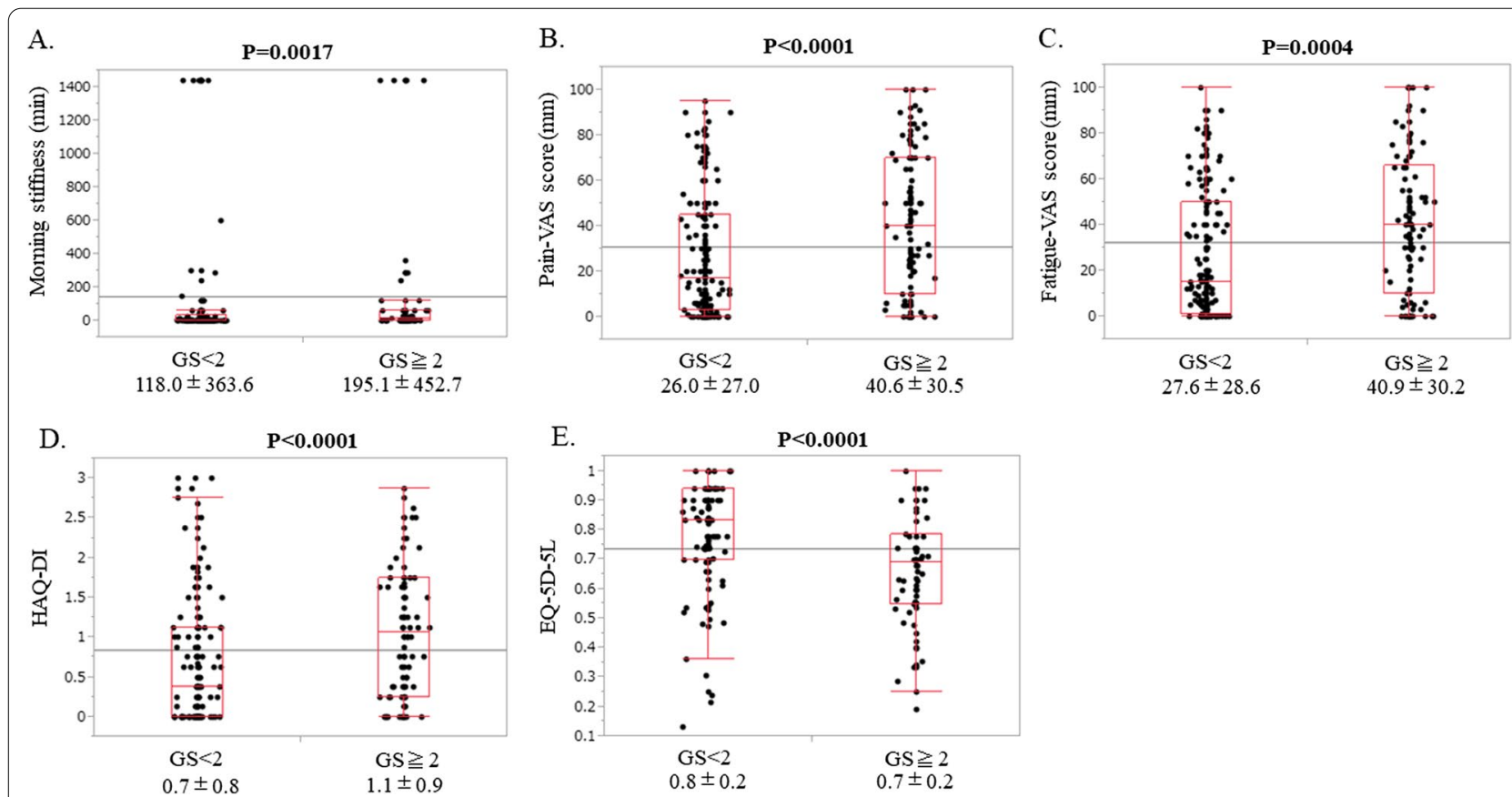

Fig. 1 Relevance to each PRO at GS score $\geq 2$ and GS score <2. A Stratified analysis of morning stiffness: GS score $\geq 2$ group, $195.1 \pm 452.7$ min; GS score $<2$ group, $118.0 \pm 363.6 \mathrm{~min}(\mathrm{P}=0.0017)$. B Stratified analysis of pain VAS score: GS score $\geq 2$ group, $40.6 \pm 30.5 \mathrm{~mm} ; \mathrm{GS}$ score $<2$ group, $26.0 \pm 27.0 \mathrm{~mm}(\mathrm{P}<0.0001)$. C Stratified analysis of fatigue VAS score: GS score $\geq 2$ group, $40.9 \pm 30.2 \mathrm{~mm}$; GS score $<2$ group, $27.6 \pm 28.6 \mathrm{~mm}$ $(P=0.0004)$. D Stratified analysis of HAQ-DI: GS score $\geq 2$ group, $1.1 \pm 0.9$; GS score $<2$ group, $0.7 \pm 0.8(P<0.0001)$. E Stratified analysis of EQ-5D-5L: GS score $\geq 2$ group, $0.7 \pm 0.2$; GS score $<2$ group, $0.8 \pm 0.2$ ( $<<0.0001$ ). GS, grayscale; VAS, visual analog scale; means $\pm S D$ s are shown 
Table 4 Patient background by LDA and REM groups

\begin{tabular}{|c|c|c|c|}
\hline Characteristics & $\operatorname{LDA}(\mathrm{N}=96)$ & $\operatorname{REM}(\mathrm{N}=99)$ & p-value \\
\hline Age, years & $65.1 \pm 15.9$ & $65.8 \pm 13.2$ & 0.9215 \\
\hline Female, \% & 86.3 & 76.8 & 0.0872 \\
\hline Disease duration, months & $119.2 \pm 122.2$ & $83.4 \pm 76.9$ & 0.0587 \\
\hline Stage $(|/| I / I I I / I V), \%$ & $43.2 / 28.4 / 13.7 / 14.7$ & $48.5 / 33.3 / 11.1 / 7.1$ & 0.3061 \\
\hline TJC, 0-28 & $1.5 \pm 1.4$ & $0.3 \pm 0.6$ & $<.0001$ \\
\hline SJC, $0-28$ & $0.5 \pm 0.7$ & $0.1 \pm 0.3$ & $<.0001$ \\
\hline $\mathrm{CRP}, \mathrm{mg} / \mathrm{dL}$ & $0.3 \pm 0.9$ & $0.2 \pm 0.3$ & 0.3908 \\
\hline $\mathrm{ESR}, \mathrm{mm} / \mathrm{h}$ & $21.0 \pm 21.7$ & $15.9 \pm 11.3$ & 0.5458 \\
\hline $\mathrm{RF}, \mathrm{IU} / \mathrm{mL}$ & $99.0 \pm 207.2$ & $86.2 \pm 128.2$ & 0.8770 \\
\hline RF positive, $\%$ & 65.3 & 54.0 & 0.1280 \\
\hline $\mathrm{CCP}, \mathrm{U} / \mathrm{mL}$ & $229.8 \pm 316.2$ & $189.0 \pm 297.5$ & 0.2574 \\
\hline CCP positive, $\%$ & 70.6 & 62.4 & 0.2455 \\
\hline $\mathrm{MMP}-3, \mathrm{ng} / \mathrm{mL}$ & $88.1 \pm 86.7$ & $70.5 \pm 75.0$ & 0.1419 \\
\hline SDAI & $6.8 \pm 2.0$ & $1.3 \pm 1.0$ & $<.0001$ \\
\hline MTX use, \% & 78.9 & 60.6 & 0.0052 \\
\hline MTX, mg/w & $8.0(3.0,10.0)$ & $6.0(0.0,8.0)$ & 0.0052 \\
\hline PSL use, \% & 8.4 & 15.2 & 0.1584 \\
\hline$P S L, m g / d$ & $0.0(0.0,0.0)$ & $0.0(0.0,0.0)$ & 0.1472 \\
\hline $\mathrm{b}(\mathrm{ts}) \mathrm{DMARD}$ use, $\%$ & 44.2 & 40.4 & 0.5916 \\
\hline HAQ-DI & $0.8 \pm 0.7$ & $0.3 \pm 0.6$ & $<.0001$ \\
\hline EQ-5D-5L & $0.8 \pm 0.2$ & $0.9 \pm 0.2$ & $<.0001$ \\
\hline MS, min & $74.1 \pm 260.2$ & $19.5 \pm 145.6$ & $<.0001$ \\
\hline Pain VAS score, $0-100, \mathrm{~mm}$ & $28.0 \pm 18.7$ & $4.5 \pm 6.7$ & $<.0001$ \\
\hline Fatigue VAS score, 0-100, mm & $33.1 \pm 23.2$ & $4.9 \pm 7.3$ & $<.0001$ \\
\hline $\mathrm{EGA}, 0-100, \mathrm{~mm}$ & $10.9 \pm 7.4$ & $2.0 \pm 3.2$ & $<.0001$ \\
\hline GS sum & $2.5 \pm 3.5$ & $1.2 \pm 2.0$ & 0.0009 \\
\hline GS score $\geq 1, \%$ & 69.5 & 44.4 & 0.0004 \\
\hline GS score $\geq 2, \%$ & 31.6 & 16.2 & 0.0116 \\
\hline GS score $\geq 3, \%$ & 11.6 & 5.1 & 0.0984 \\
\hline PD sum & $1.0 \pm 2.1$ & $0.3 \pm 1.1$ & 0.0005 \\
\hline PD score $\geq 1, \%$ & 33.7 & 12.1 & 0.0003 \\
\hline PD score $\geq 2, \%$ & 17.9 & 9.1 & 0.0720 \\
\hline PD score $\geq 3, \%$ & 3.2 & 2.0 & 0.6171 \\
\hline
\end{tabular}

Results are shown as mean $\pm \mathrm{SD}$; TJC, tender joint count; SJC, swollen joint count; CRP, C-reactive protein; ESR, erythrocyte sedimentation rate; RF, rheumatoid factor; CCP, cyclic citrullinated peptide; MMP-3, matrix metalloproteinase-3; SDAl, Simplified Disease Activity Index; MTX, methotrexate; PSL, prednisolone; b(ts)DMARD, biological (targeted synthetic) disease-modifying antirheumatic drug; HAQ-DI, Health Assessment Questionnaire Disability Index; EQ-5D-5L, European Quality of Life-5 Dimensions; MS, morning stiffness; VAS, visual analog scale; EGA, evaluator global assessment of disease activity; GS, grayscale; PD, power Doppler; LDA, low disease activity; REM: remission

Table 5 Multivariate logistic analysis of the LDA and REM groups

\begin{tabular}{|c|c|c|c|c|c|}
\hline & Estimated value & Standard error & Chi-square & Confidence interval & $\mathbf{P}$ \\
\hline Intercept & 4.4074 & 0.7313 & 36.33 & 3.1218 to 6.0267 & $<.0001$ \\
\hline TJC & -2.0812 & 0.4008 & 26.96 & -2.9545 to -1.3682 & $<.0001$ \\
\hline MTX dose (mg/w) & -0.0652 & 0.0606 & 1.16 & -0.1881 to 0.0526 & 0.2818 \\
\hline Fatigue VAS score (mm) & -0.1667 & 0.0300 & 30.79 & -0.2357 to -0.1161 & $<.0001$ \\
\hline GS score $\geq 2$ : yes, 1 ; no, 0 & 0.2049 & 0.3439 & 0.36 & -0.4740 to 0.8878 & 0.5512 \\
\hline
\end{tabular}

TJC, tender joint count; LDA, low disease activity; MTX, methotrexate; REM: remission; VAS, visual analog scale; GS, grayscale 


\section{Discussion}

This study comprised a relatively well-controlled group (overall mean SDAI, 10.6) of patients with established RA (mean disease duration, 103.6 months). This is the first study to examine the association between US images and PROs in the treatment of RA.

In order to examine the relationship between disease activity and US images, first, we divided the analysis into two groups: those who achieved LDA and those who did not, as is the minimum goal of the EULAR recommendation $[18,19]$. In our study, PROs and GS score $\geq 2$ remained in the analysis of HDA/MDA vs LDA/REM. Subsequently, the analysis was divided into REM and LDA. However, GS score $\geq 2$ was absent in the analysis of LDA vs REM. Initially, residual US-induced inflammation was assumed to be present in patients in the REM group; however, analysis showed no US-induced inflammation, which supports previous reports. Moreover, residual US-induced inflammation was found in patients who achieved LDA.

Previous studies have shown the association between PD and GS scores in patients with clinical REM and prognosis or disease activity. The presence of persistent PD signals in patients with clinical REM has been associated with early relapse of RA $[20,21]$. One study identified the GS score as a predictor of erosion progression in patients with REM [22]. Our study identified GS score $\geq 2$ as an independent factor for patients who achieved LDA during treatment, but showed persistent inflammation after treatment. Additionally, the results showed a relationship between GS $\geq 2$ and PROs. Several studies of PROs, disease burden, pain, fatigue, and mental burden of patients with RA have reported significant residual symptoms and disease burden experienced by patients with REM or LDA [23]. Current evaluations of the disease activity for RA are based on only a few symptoms and laboratory test values. Therefore, even after achieving LDA or clinical REM, some patients may experience residual symptoms that significantly affect their daily and social activities, and other patients may not be fully satisfied with their treatment due to overlooked subjective symptoms.

In our study, patients with RA who achieved LDA or clinical REM experienced residual symptoms, including pain, fatigue, morning stiffness, mental health, and functional disability, possibly due to inflammation or other psychological effects of the disease itself. Thus, our study is consistent with several studies on residual symptoms experienced by patients with RA who achieved LDA and clinical REM [23, 24].

One study that assessed residual symptoms in patients with RA using MRI [24] showed that increases in synovitis, osteitis, and bone erosions indicated a positive correlation with HAQ at all time points, with pain and patient global scores at 24 and 52 weeks, respectively. Synovitis was associated with HAQ, pain, and patient global scores at all time points, independent of the predictors of clinical disease activity. Weak improvements in synovitis and erosion progression on MRI at week 52 were associated with worsening PROs, not with the progression as measured by X-ray examination. The report showed an independent association between weak improvement in synovitis and worsening pain and overall patient evaluation in the study, which is consistent with the results of our research (i.e., all significantly persistent morning stiffness, pain, and fatigue with GS score $\geq 2$ ).

Our research has some limitations. First, it was a single-centre study with an inherent selection bias, and the cross-sectional analysis involved subjective evaluation indicators. We considered that the relevance would be strengthened by observing the variations in both objective and subjective evaluation indicators over time. Second, we evaluated only the hand and finger joints bilaterally using US; nevertheless, these joints are the largest preferred sites for RA. Third, we did not validate the presence of additional synovitis found by MRI or other imaging techniques. However, these techniques are limited by the inability to scan multiple joints or a lack of specificity.

In conclusion, this is the first report on patients with RA undergoing treatment wherein MSUS assessment was considered important when patients reached LDA, whereas residual inflammation was rarely observed on MSUS when patients achieved REM. REM induction is not only important in preventing joint destruction, but also in improving QoL and subjective symptoms. Future research is required for evaluating additional joints or using MRI as a sensitive imaging modality.

\section{Abbreviations \\ CRP: C-reactive protein; DMARD: Disease-modifying antirheumatic drug; ESR: Erythrocyte sedimentation rate; EQ-5D-5L: European Quality of Life-5 Dimen- sions; EULAR: European League Against Rheumatism; GS: Grayscale; HDA: High disease activity; HAQ-DI: Health Assessment Questionnaire Disability Index; LDA: Low disease activity; MDA: Moderate disease activity; MMP-3: Matrix metalloproteinase-3; MRI: Magnetic resonance imaging; MTX: Methotrexate; MSUS: Musculoskeletal ultrasonography; PD: Power doppler; PRO: Patient- reported outcome; QoL: Quality of life; RA: Rheumatoid arthritis; REM: Remis- sion; SJC: Swollen joint count; TJC: Tender joint count; T2T: Treat-to-target; VAS: Visual analog scale.}

\section{Acknowledgements}

The authors thank all medical staff at Tobata General Hospital for collecting the data. In addition, we thank Kenta Awakura and Kohei Hagimori of Eli Lilly Japan K.K.

\section{Authors' contributions}

MN contributed to the study design, overall review, and the writing of the manuscript. The other authors were involved in conducting the study and reviewing the manuscript. YT and KS participated in the study design and coordination. MN, Kazuki Someya, MF, YF, AN, and KS enrolled and managed patients in the hospital. All authors read and approved the final manuscript. 


\section{Funding}

This work was supported by Eli Lilly Japan K.K.

\section{Availability of data and materials}

The datasets generated during and analysed during the current study are not public due to the nature of this research. As the participants of this study did not agree for their data to be shared publicly, supporting data are not available publicly, but are available from the corresponding author on reasonable request.

\section{Declarations}

\section{Ethics approval and consent to participate}

The study and its retrospective observation design was approved by the Ethics Committee of the Japan Physicians Association, and informed consent was obtained from all patients. The research was conducted in accordance with the Ethical Guidelines for Medical and Health Research Involving Human Subjects.

\section{Consent for publication}

Not applicable.

\section{Competing interests}

YT has received consulting fees, speaking fees, and/or honoraria from Abbvie, Daiichi-Sankyo, Chugai, Takeda, Mitsubishi-Tanabe, Bristol-Myers, Astellas, Eisai, Janssen, Pfizer, Asahi-kasei, Eli Lilly, GlaxoSmithKline, UCB, Teijin, MSD, and Santen and has received research grants from Mitsubishi-Tanabe, Takeda, Chugai, Astellas, Eisai, Taisho-Toyama, Kyowa-Kirin, Abbvie, and Bristol-Myers. KS and MN have received research funding from Eli Lilly Japan K.K. Kazuki Someya, MF, YF and AN have no conflict of interest.

\section{Author details}

${ }^{1}$ Department of Clinical Immunology and Rheumatology, Tobata General Hospital, Kitakyushu, Japan. ${ }^{2}$ The First Department of Internal Medicine, School of Medicine, University of Occupational and Environmental Health, 1-1 Iseigaoka, Yahata-nishi-ku, Kitakyushu, Fukuoka 807-8555, Japan.

Received: 7 May 2021 Accepted: 2 August 2021

Published online: 22 November 2021

\section{References}

1. Scott DL, Wolfe F, Huizinga TWJ. Rheumatoid arthritis. Lancet. 2010;376:1094-108.

2. Ishida M, Kuroiwa Y, Yoshida E, Sato M, Krupa D, Henry N, et al. Residual symptoms and disease burden among patients with rheumatoid arthritis in remission or low disease activity: a systematic literature review. Mod Rheumatol. 2018;28:789-99.

3. Colebatch AN, Edwards CJ, Østergaard M, Van der Heijde D, Balint PV, D'Agostino MA, et al. EULAR recommendations for the use of imaging of the joints in the clinical management of rheumatoid arthritis. Ann Rheum Dis. 2013;72:804-14.

4. Geenen R, Overmaz CL, Christensen R, Åsenlöf P, Capela S, Huisinga KL, et al. EULAR recommendations for the health professional's approach to pain management in inflammatory arthritis and osteoarthritis. Ann Rheum Dis. 2018;77:797-807.

5. U.S. Department of Health and Human Services FDA Center for Drug Evaluation and Research; U.S. Department of Health and Human Services FDA Center For Biologics Evaluation and Research; U.S. Department of Health and Human Services FDA Center For Devices And Radiological Health. Guidance for industry: patient-reported outcome measures: use in medical product development to support labeling claims: draft guidance. Health Qual Life Outcomes. 2006:4:79.

6. Szkudlarek M, Court-Payen M, Strandberg C, Klarlund M, Klausen T, Østergaard M. Power Doppler ultrasonography for assessment of synovitis in the metacarpophalangeal joints of patients with rheumatoid arthritis: a comparison with dynamic magnetic resonance imaging. Arthritis Rheum. 2001;44:2018-23.
7. Terslev L, Torp-Pedersen S, Savnik A, Von der Recke P, Qvistgaard E, Danneskiold-Samsøe B, et al. Doppler ultrasound and magnetic resonance imaging of synovial inflammation of the hand in rheumatoid arthritis: a comparative study. Arthritis Rheum. 2003;48:2434-41.

8. Arnett FC, Edworthy SM, Bloch DA, McShane DJ, Fries JF, Cooper NS, et al. The American Rheumatism Association 1987 revised criteria for the classification of rheumatoid arthritis. Arthritis Rheum. 1988;31:315-24.

9. Aletaha D, Neogi T, Silman AJ, Funovits J, Felson DT, Bigham CO, et al. 2010 rheumatoid arthritis classification criteria: an American College of Rheumatology/European League Against Rheumatism collaborative initiative. Ann Rheum Dis. 2010;69:1580-8.

10. Aletaha D, Neogi T, Silman AJ, Funovits J, Felson DT, Bigham CO, et al. 2010 Rheumatoid arthritis classification criteria: an American College of Rheumatology/European League Against Rheumatism collaborative initiative. Arthritis Rheum. 2010;62:2569-81.

11. Backhaus M, Burmester GR, Gerber T, Grassi W, Machold KP, Swen WA, et al. Guidelines for musculoskeletal ultrasound in rheumatology. Ann Rheum Dis. 2001;60:641-9.

12. Szkudlarek M, Court-Payen $M$, Jacobsen S, Klarlund M, Thomsen HS, Østergaard M. Interobserver agreement in ultrasonography of the finger and toe joints in rheumatoid arthritis. Arthritis Rheum. 2003;48:955-62.

13. Aletha D, Smolen J. The Simplified Disease Activity Index (SDAI) and the Clinical Disease Activity Index (CDAl): a review of their usefulness and validity in rheumatoid arthritis. Clin Exp Rheumatol. 2005;23:S100-8.

14. Anderson J, Caplan L, Yazdany J, Robbins ML, Neogi T, Michaud K, et al. Rheumatoid arthritis disease activity measures: American College of Rheumatology recommendations for use in clinical practice. Arthritis Care Res. 2012;64:640-7.

15. Fries JF, Spitz P, Kraines RG, Holman HR. Measurement of patient outcome in arthritis. Arthritis Rheum. 1980;23:137-45.

16. Oppe M, Devlin NJ, Van Hout B, Krabbe PFM, De Charro F. A program of methodological research to arrive at the new international EQ-5D-5L valuation protocol. Value Health. 2014;17:445-53.

17. Ikeda S, Shiroiwa T, Igarashi A. Developing a Japanese version of the EQ-5D-5L value set. J Natl Inst Public Health. 2015;64:47-55.

18. Smolen JS, Aletaha D, Bijlsma JW, Breedveld FC, Boumpas D, Burmester $\mathrm{G}$, et al. Treating rheumatoid arthritis to target: recommendations of an international task force. Ann Rheum Dis. 2010;69:631-7.

19. Smolen JS, Landewe RBM, Bijlsma JWJ, Burmester GR, Dougados M Kerschbaumer $A$, et al. EULAR recommendations for the management of rheumatoid arthritis with synthetic and biological disease-modifying antirheumatic drugs: 2019 update. Ann Rheum Dis. 2020;79:685-99.

20. Saleem B, Brown AK, Quinn M, Karim Z, Hensor EMA, Conaghan P, et al. Can flare be predicted in DMARD treated RA patients in remission, and is it important? A cohort study. Ann Rheum Dis. 2012;71:1316-21.

21. Scirè CA, Montecucco C, Codullo V, Epis O, Todoerti M, Caporali R. Ultrasonographic evaluation of joint involvement in early rheumatoid arthritis in clinical remission: power Doppler signal predicts short-term relapse. Rheumatology. 2009;48:1092-7.

22. Saleem B, Brown AK, Keen H, Nizam S, Freeston J, Karim Z, et al. Disease remission state in patients treated with the combination of tumor necrosis factor blockade and methotrexate or with disease-modifying antirheumatic drugs: a clinical and imaging comparative study. Arthritis Rheum. 2009:60:1915-22.

23. D'Agostino MA, Terslev L, Wakefield R, Østergaard M, Balint P, Naredo $E$, et al. Novel algorithms for the pragmatic use of ultrasound in the management of patients with rheumatoid arthritis: from diagnosis to remission. Ann Rheum Dis. 2016;75:1902-8.

24. Baker JF, Conaghan PG, Emery P, Baker DG, Ostergaard M. Relationship of patient-reported outcomes with MRI measures in rheumatoid arthritis. Ann Rheum Dis. 2017;76:486-90.

\section{Publisher's Note}

Springer Nature remains neutral with regard to jurisdictional claims in published maps and institutional affiliations. 